\title{
Social position and geriatric syndromes among Swedish older people: a population-based study
}

\author{
C. Rausch ${ }^{1,2^{*}}$ (D) Y. Liang ${ }^{1}$, U. Bültmann², S. E. de Rooij ${ }^{3}$, K. Johnell ${ }^{4}$, L. Laflamme ${ }^{1}$ and J. Möller ${ }^{1}$
}

\begin{abstract}
Background: Older people with a low social position are at higher risk of poor health outcomes compared to those with a higher social position. Whether lower social position also increases the risk of geriatric syndromes (GSs) remains to be determined. This study investigates the association of social position with GSs among older community-dwellers.

Methods: Three consecutive population-based health surveys in 2006, 2010 and 2014 among older communitydwellers (age 65-84 years) in Stockholm County were combined $(n=17,612)$ and linked with Swedish administrative registry information. Social position was assessed using registry information (i.e. education, country of origin and civil status) and by self-reports (i.e. type of housing and financial stress). GSs were assessed by selfreports of the following conditions: insomnia, urinary incontinence, functional decline, falls, depressive disorder, hearing or vision problems. Binomial logistic regression analyses were used to estimate the association between social position and GSs after adjusting for age, sex, health status, health behavior and social stress.
\end{abstract}

Results: The prevalence of GSs was 70.0\%, but varied across GSs and ranged from 1.9\% for depression to 39.1\% for insomnia. Living in rented accommodation, being born outside the Nordic countries, being widowed or divorced were associated with GS presence. Financial stress was most strongly associated with GSs (adjusted odds ratio, 2.59; $95 \% \mathrm{Cl}, 2.13-3.15)$.

Conclusion: GSs are highly prevalent among older Swedish community-dwellers with wide variations across syndromes and strong association with all measures of social position, most strikingly that of experiencing financial stress.

Keywords: Geriatric syndromes, Health inequality, Socio-economic status, Social position, Elderly

\section{Background}

Older people typically have both age-dependent conditions, like functional decline, and chronic ones, like cardiovascular diseases $[1,2]$. Their co-occurrence challenges outcome specific clinical and public health interventions [2, 3]. Modifiable factors like health behavior and social isolation, but also less modifiable factors like social position play a role in the occurrence of these conditions $[1,4,5]$. While

\footnotetext{
* Correspondence: christian.rausch@ki.se

${ }^{1}$ Department of Public Health Sciences, Karolinska Institutet, Widerströmska huset 4:th floor, Tomtebodavägen 18A, 17177 Stockholm, SE, Sweden ${ }^{2}$ Department of Health Sciences, Community and Occupational Medicine, University of Groningen, University Medical Center Groningen, Antonius Deusinglaan 1, FA10, 9713, AV, Groningen, The Netherlands Full list of author information is available at the end of the article
}

there are several social position measures that have a documented direct association with health for both general and chronic conditions, e.g. level of education or income [1, $4,6,7]$, less is known about how they relate to agedependent conditions.

One group of age-dependent conditions that warrants closer investigation in that respect is geriatric syndromes (GSs) (e.g. loss of hearing and vision or urinary incontinence) [7-9]. Presence of geriatric syndromes marks older peoples' frail state. Acting on these syndromes may prevent serious deterioration of existing chronic conditions, as well as the decline in functional disabilities and dependence [2,10-12]. Time of onset and severity of GSs may be influenced by older people's health, social stress

(c) The Author(s). 2019 Open Access This article is distributed under the terms of the Creative Commons Attribution 4.0 International License (http://creativecommons.org/licenses/by/4.0/), which permits unrestricted use, distribution, and 
and health-related behaviors, all of which are closely related to their social position $[1,5,12-14]$. Various measures of social position like education, income, but also civil status have different effect on GSs $[1,8,13$, 15]. However, knowledge on the association between social position and geriatric syndromes is scarce and an investigation into a combination of GSs and measures of social position may provide valuable overview into their relationship. To our knowledge, no previous study has considered this association in the context of Sweden.

GSs have been defined as multifactorial health conditions that visualize and contribute to older peoples underlying frailty $[10,16]$. As such they present an increased level of vulnerability for situational challenges due to aging processes and accumulated impairments [10]. While GSs are pluriform and prevalent among community-dwellers $[17,18]$, they are difficult to manage clinically $[5,10,17,19]$, and put older people at increased risk not only for developing new chronic conditions, but also for hospitalization and/ or institutionalization [12]. Various GSs share risk factors and etiologies like older age or impaired mobility [10, 18]. Specific GSs, like falls and urinary incontinence, have been extensively studied and their relation with future health outcomes, such as increased mortality, and decreased quality of life is well established $[10,18,20,21]$. Other GSs, like the course of functional decline and insomnia have been studied to a lesser extend [10, 22]. However, studies combining several types of GS are rare $[12,18,19]$, as consensus on a clear universal definition for GSs is lacking [10, 12]. Studying GSs as a set, rather than individual or specific GSs, helps to get a better understanding of other determinants involved such as health factors and social factors [23]. This approach also helps to study the influence of social position on GSs, which may identify health inequalities in regards to the existence of GSs among older people living in society [10].

In this study, we therefore aim to determine the prevalence of GSs and the associations between social position and GSs among older community-dwellers, taking into account health status, health-related behavior and social stress.

\section{Methods}

\section{Study design and sample}

Data was drawn from three cross-sectional Stockholm County Council Public Health Surveys (i.e. 2006, 2010, and 2014) in Stockholm County, with study design and sample selection previously published (see Additional file 1, [24]). The Public Health Surveys were conducted every four years among approximately 50,000 individuals aged $18-84$ years (from 2010, individuals above 84 years were also included).

In the current study, the sample was restricted to people aged 65 to 84 years $(n=18,592)$. The final study population consists of 17,612 participants, excluding those with missing information on GS items $(n=980)$, but including those with missing data on GSs items that do report having at least one GS items present. Among those, the response rates were $74.5 \%(n=6713), 74.1 \%$ $(n=7153)$ and $60.1 \%(n=4726)$ in 2006, 2010 and 2014 respectively. Data from self-reports were linked with Swedish registers: the database for health insurance and labor market studies (LISA).

\section{Measures}

Information on GSs and social position, including type of housing and financial stress, was based on self-reported questionnaires. Information on the other measures of social position, including education, civil status and country of origin, was extracted from the LISA register.

\section{Geriatric syndromes}

Seven GSs were assessed [10, 18], including injurious falls in the last six months, urinary incontinence (urinary leakage), functional decline (inability to: run $100 \mathrm{~m}$, as well as walking $100 \mathrm{~m}$ or taking stairs), severe hearing problems (despite using hearing aids), severe vision problems (despite the use of glasses), insomnia (light to heavy sleeping difficulties) and signs of depressive disorders (measured by the 12-item General Health Questionnaire [GHQ], Goldberg et al. 1988) [25]. The GHQ12 is a validated screening device for minor psychiatric conditions. Answering "yes" to at least one GSs, or having a GHQ score $>8$ for depressive disorder, defined the presence of a GSs.

\section{Social position}

Social position was assessed by five measures: level of education, civil status, country of birth, type of housing and financial stress. Level of education was categorized as university degree (more than twelve years of education), secondary school (ten to twelve years of education) or primary school ( equal to or less than nine years of education). Civil status was categorized into married, unmarried, divorced and widowed. Country of birth was measured as Sweden, other Nordic countries, other European countries, and the rest of the world. Type of housing was measured as owning an accommodation or housing, rental accommodation or others including second-hand rentals, assisted-communal living and student housing. Financial stress was present when participants indicated to have struggled to buy food, pay bills, rent or things of similar nature in the last 12 months. The measures were separately assessed in their association with GSs and based on previously applied models of social position and inequality in health included the WHO PROGRESS framework [1, 26, 27]. 


\section{Confounders}

Potential confounders were age, sex, and indicators of the following domains; health status, health behavior and social stress which have previously been shown to related to GSs and social position [4, 13]. The selection of domains and indicators was based on earlier literature on health and life conditions among elderly in Stockholm $[5,28]$.

Information on age and sex was extracted from the LISA Register. Information on health status, health behavior and social stress was based on self-reports from the Stockholm County Council Public Health Surveys.

Health status was assessed via different proxies: selfreported diagnosis of at least one chronic condition (including diabetes, chronic obstructive pulmonary disease, hypertension, hyperlipidemia, angina pectoris, heart failure, myocardial infarction or stroke), body mass index (BMI) and general self-rated health. The BMI was categorized into obesity $\left(>29.99 \mathrm{~kg} / \mathrm{m}^{2}\right)$, overweight $(29.99$ $\left.24.99 \mathrm{~kg} / \mathrm{m}^{2}\right)$, normal weight $\left(24.99-18.50 \mathrm{~kg} / \mathrm{m}^{2}\right)$, and underweight $\left(<18.50 \mathrm{~kg} / \mathrm{m}^{2}\right)$. Self-rated health was measured with the first question of the SF36 and dichotomized into very good, good and moderate, or bad and very bad [29].

Health behavior was assessed with four dichotomized proxies including poor dietary habit (less than 2 pieces of fruit or vegetables per month), sedentary lifestyle (more than half of the day sitting), alcohol binge drinking (more than one bottle of wine or equivalent per week) and current tobacco use (cigarettes or other tobacco products).

Social stress was measured by four different proxies consisting of yes and no questions. Confirmatory answers to questions on the living situation (living alone), social support (lack thereof), social participation (social inactivity) and trust in the neighbors (distrusting their neighbor) served as indicators for social stress [5].

\section{Statistical analyses}

The prevalence of GSs was presented for the entire study sample and stratified by age and sex. Chi-square tests were performed for comparison between the stratified groups. Bivariate analyses were conducted examining the relationship between health status, health behavior and social stress. Due to high correlations among health status indicators, only the presence of a chronic condition was used in adjustments.

The associations between different measures of social position and presence of a GS were examined using binomial logistic regression (odds ratios [ORs] and 95\% confidence interval $[\mathrm{CI}])$. First, all analyses were adjusted for age and sex. In a next step, the analyses were further adjusted for chronic conditions (model 1), health behavior (model 2), chronic conditions and health-behavior (model 3), and finally chronic conditions, health behavior and social stress (model 4).

Missing information on covariates was treated as a separate category in the analysis. Missing information ranged mainly from 0.1 to $6.0 \%$. However, data on level of education, tobacco use and alcohol use had missing information of 12.3, 13.4 and $12.3 \%$ respectively.

IBM SPSS Statistics 24 for Windows (IBM SPSS Inc., Chicago, Illinois, USA) was used for all statistical analyses.

\section{Results}

In total, 12,333 (70.0\%) older community-dwellers reported at least one GS. Table 1 shows insomnia as the most commonly reported GS (39.1\%). GSs were more prevalent among women, except for severe hearing loss (men $22.3 \%$ vs. women $19.6 \%$ ). Further, a higher prevalence of GSs was found among older community-dwellers with obesity or underweight, and those indicating to have a chronic condition (Table 2). GSs were particularly

Table 1 Prevalence (\%) of geriatric syndrome; by sex and age groups $(n=17,612)$

\begin{tabular}{|c|c|c|c|c|c|c|c|c|c|}
\hline \multirow[t]{2}{*}{ Type of GS } & \multirow[t]{2}{*}{ Total } & \multicolumn{3}{|l|}{ Sex } & \multicolumn{5}{|c|}{ Age group (years) } \\
\hline & & $\begin{array}{l}\text { Male } n= \\
8117\end{array}$ & $\begin{array}{l}\text { Female } n= \\
9495\end{array}$ & $\begin{array}{l}p \\
\text { value }^{a}\end{array}$ & $\begin{array}{l}65-69 n= \\
6248\end{array}$ & $\begin{array}{l}70-74 n= \\
5130\end{array}$ & $\begin{array}{l}75-79 n= \\
3617\end{array}$ & $\begin{array}{l}80-84 n= \\
2617\end{array}$ & $\begin{array}{l}p \\
\text { value }\end{array}$ \\
\hline Insomnia & 39.1 & 30.4 & 46.6 & $<0.01$ & 36.8 & 40.2 & 40.4 & 40.7 & $<0.01$ \\
\hline Incontinence & 26.4 & 19.2 & 32.6 & $<0.01$ & 20.5 & 25.8 & 29.7 & 37.1 & $<0.01$ \\
\hline Severe hearing problem & 20.8 & 22.3 & 19.6 & $<0.01$ & 19.0 & 19.9 & 21.9 & 25.6 & $<0.01$ \\
\hline Functional decline & 20.4 & 16.2 & 23.9 & $<0.01$ & 11.1 & 16.9 & 26.1 & 41.2 & $<0.01$ \\
\hline Fall & 10.5 & 8.9 & 12.0 & $<0.01$ & 7.0 & 10.2 & 12.2 & 17.3 & $<0.01$ \\
\hline Severe vision problem & 4.2 & 3.8 & 4.6 & $<0.01$ & 2.6 & 3.7 & 4.7 & 8.5 & $<0.01$ \\
\hline Depressive disorder & 1.9 & 1.5 & 2.3 & $<0.01$ & 1.5 & 1.7 & 2.4 & 2.8 & $<0.01$ \\
\hline $\begin{array}{l}\text { At least one geriatric } \\
\text { syndrome }\end{array}$ & 70.0 & 62.4 & 76.5 & $<0.01$ & 62.3 & 69.2 & 75.2 & 83.0 & $<0.01$ \\
\hline
\end{tabular}

Note

${ }^{a} p$-value of Pearson Chi-square tests for comparison of distribution 
Table 2 Prevalence and 95\% Cl of geriatric syndrome by different characteristics of the study population $(n=17,612)$

\begin{tabular}{|c|c|c|c|}
\hline \multirow[t]{2}{*}{ Characteristics } & \multirow[t]{2}{*}{ Category } & \multicolumn{2}{|c|}{ Geriatric syndrome $^{a}$} \\
\hline & & $n$ & $\%$ \\
\hline \multicolumn{4}{|l|}{ Health status } \\
\hline \multirow[t]{2}{*}{ Self-rated health } & Very good, good and moderate & 10,834 & 67.7 \\
\hline & Bad and very bad & 1199 & 97.9 \\
\hline \multirow[t]{4}{*}{ BMl status } & Obese & 1771 & 78.6 \\
\hline & Overweight & 4654 & 68.8 \\
\hline & Normal & 5181 & 67.5 \\
\hline & Underweight & 210 & 76.1 \\
\hline \multirow[t]{2}{*}{ Chronic conditions } & No & 4315 & 63.0 \\
\hline & Yes & 7827 & 74.3 \\
\hline \multicolumn{4}{|l|}{ Health behavior } \\
\hline \multirow[t]{2}{*}{ Poor dietary habit } & No & 10,431 & 68.8 \\
\hline & Yes & 1066 & 74.6 \\
\hline \multirow[t]{2}{*}{ Sedentary lifestyle } & No & 9943 & 67.2 \\
\hline & Yes & 1949 & 86.4 \\
\hline \multirow[t]{2}{*}{ Alcohol binge drinking } & No & 9540 & 68.4 \\
\hline & Yes & 986 & 74.5 \\
\hline \multirow[t]{2}{*}{ Current Tobacco user } & No & 9073 & 69.7 \\
\hline & Yes & 1713 & 70,7 \\
\hline \multicolumn{4}{|l|}{ Social stress } \\
\hline \multirow[t]{2}{*}{ Living alone } & No & 7737 & 66.3 \\
\hline & Yes & 4493 & 77.2 \\
\hline \multirow[t]{2}{*}{ Lack of social support } & No & 10,528 & 68.8 \\
\hline & Yes & 1495 & 77.8 \\
\hline \multirow[t]{2}{*}{ Socially inactive } & No & 6321 & 66.5 \\
\hline & Yes & 5310 & 74.1 \\
\hline \multirow[t]{2}{*}{ Distrust in neighborhood } & No & 11,342 & 69.2 \\
\hline & Yes & 739 & 80.6 \\
\hline
\end{tabular}

Note

${ }^{\text {a }}$ Reported at least one geriatric syndrome

prevalent among those who rated their health as bad or very bad $(n=1199,97.9 \%)$.

Among the measures of social position, GS were most prevalent among older people with financial stress (87.7\%) (Table 3). All measures of social position were significantly associated with presence of GS (Table 3), when adjusting only for age and sex. Financial stress showed the strongest association with GSs (OR, 3.33; 95\% CI, 2.75-4.03).

Financial stress remained strongly associated with GSs after adjustments for health status, i.e. chronic conditions and health behavior. Primary and secondary school education, and unmarried older people did not remain associated with GSs (Table 4) after taking chronic conditions and health behavior into account. Additional adjustment for social stress attenuated the associations of social position with GSs, but remained statistical significant, except for older people born outside the Nordic countries. Financial stress was most strongly associated with the presence of GSs even in the adjusted models (adj. OR, 2.59; 95\% CI, 2.13-3.15). Financial stress was also associated with most types of geriatric syndromes (Additional file 2: Table S1.).

\section{Discussion}

Our study shows that GSs were highly prevelant (70.0\%) among older community-dwellers in Stockholm County. The observerd prevalance varied acrossdifferent GSs. Older community-dwellers with self-reported financial stress, those not owning housing, as well as those that were widowed had the highest prevalence of geriatric syndromes. Presence of GSs was associated with all five measures of social position i.e. civil status, country of origin, level 
Table 3 Prevalence and odds rations (95\% Cl) for geriatric syndromes by measures of social position $(n=17,612)$

\begin{tabular}{|c|c|c|c|c|c|}
\hline \multirow[t]{2}{*}{ Characteristics } & \multirow[t]{2}{*}{ Category } & \multicolumn{4}{|c|}{ Geriatric syndromes $^{a}$} \\
\hline & & $\mathrm{n}$ & $\%$ & Odds ratio & $95 \% \mathrm{Cl}^{\mathrm{b}}$ \\
\hline \multirow[t]{4}{*}{ Age (in years) } & $65-69$ & 3892 & 62.3 & 1.00 & \\
\hline & $70-74$ & 3549 & 69.2 & 1.37 & $1.27-1.49$ \\
\hline & $75-79$ & 2721 & 75.2 & 1.81 & $1.65-1.99$ \\
\hline & $80-84$ & 2171 & 83.0 & 2.89 & $2.58-3.24$ \\
\hline \multirow[t]{2}{*}{ Sex } & Male & 5069 & 62.4 & 1.00 & \\
\hline & Female & 7264 & 76.5 & 1.93 & $1.80-2.06$ \\
\hline \multirow[t]{4}{*}{ Civil status } & Married & 6817 & 66.5 & 1.00 & \\
\hline & Unmarried & 912 & 70.3 & 1.23 & $1.08-1.40$ \\
\hline & Divorced & 2343 & 72.7 & 1.26 & $1.15-1.38$ \\
\hline & Widowed & 2257 & 79.5 & 1.29 & $1.16-1.43$ \\
\hline \multirow[t]{4}{*}{ Country of origin } & Sweden & 10,128 & 68.8 & 1.00 & \\
\hline & Other Nordic countries & 1002 & 74.7 & 1.26 & $1.11-1.44$ \\
\hline & Other European & 826 & 76.6 & 1.53 & $1.32-1.77$ \\
\hline & Rest of the world & 377 & 79.4 & 1.87 & $1.48-2.35$ \\
\hline \multirow{3}{*}{$\begin{array}{l}\text { Highest level } \\
\text { of education }\end{array}$} & University education & 3373 & 65.8 & 1.00 & \\
\hline & Upper secondary school & 4351 & 69.0 & 1.15 & $1.06-1.24$ \\
\hline & Primary school ( $\leq 9 y)$ & 2885 & 71.6 & 1.22 & $1.11-1.33$ \\
\hline \multirow[t]{3}{*}{ Type of Housing } & Own accommodation & 8620 & 67.2 & 1.00 & \\
\hline & Rented accommodation & 3209 & 76.4 & 1.43 & $1.32-1.55$ \\
\hline & Other & 374 & 83.9 & 2.24 & $1.73-2.91$ \\
\hline \multirow[t]{2}{*}{ Financial Stress - General } & No & 11,104 & 68.7 & 1.00 & \\
\hline & Yes & 904 & 87.7 & 3.33 & $2.75-4.03$ \\
\hline
\end{tabular}

Note

${ }^{a}$ Reported at least one GS

${ }^{b}$ Adjusted for sex and age

of education, type of housing and financial stress even after adjustment for age, sex and health status (i.e. chronic conditions). These associations between social position measures and geriatric syndromes remained after additional adjustments for health behavior and social stress, except for measures like education, i.e. primary and seconday school education, civil status, i.e. being unmarried and country of origin, i.e. being born outside of the nordic countries. Financial stress was by far most strongly associated with GSs. Those reporting financial stress were more than twice as common to experience GSs than those who did not.

All GSs and all participants aggregated, the high prevalence we observed compares to some extent to that reported in previous population-based studies on GSs $[12,17,18]$, with estimations up to $49.9 \%$ [18],76.3\% [17] and $80.5 \%$ [12], compared to our $70.0 \%$. The difference between studies can be a reflection of differences in either the specific GSs combined, e.g. inclusion of polypharmacy [12] or the population groups, some focusing on female community-dwellers e.g. Women's Health
Initiative Observational Study [17], people aged 75 years and older [12] or community-dwellers and nursing home residents [18]. Our study includes seven of the most common GSs [10, 17, 18, 24, 30].

In regard to specific types of GSs, varying prevalences are also noted between our results and other studies [31, 32], including vision and hearing impairment [18] and falls [17]. However, prevalences vary for some other specific GSs, e.g. the prevalence of urinary incontinence was $29.3 \%$ [17] and $9.3 \%$ [18] compared to our $26.4 \%$, which partly can be explained by the use of different definitions e.g. use of pads [18] vs. presence of urinary leakage.

When it comes to differences across social measures, it is of note that earlier studies have also shown an association between financial stress and age-dependent health conditions [4, 8, 13, 30,33-35], but not yet to prevalent GSs in general, a potential indicator of upcoming new health conditions $[10,17,18]$. A previous study has shown a high prevalence of GSs among people in poverty [13], and studies on specific types of GSs have shown an increased risk with financial stress and also type of housing [34, 35]. A range of factors can explain 
Table 4 Association between social position and geriatric syndromes, adjusted odd ratios and 95\% Cl

\begin{tabular}{|c|c|c|c|c|}
\hline & Model 1 & Model 2 & Model 3 & Model 4 \\
\hline \multicolumn{5}{|l|}{ Civil status } \\
\hline Married & 1.00 & 1.00 & 1.00 & 1.00 \\
\hline Unmarried & $1.25(1.10-1.43)$ & $1.11(0.97-1.27)$ & $1.14(1.00-1.30)$ & $1.06(0.93-1.20)$ \\
\hline Divorced & $1.26(1.15-1.38)$ & $1.16(1.06-1.27)$ & $1.16(1.06-1.27)$ & $1.11(1.01-1.22)$ \\
\hline Widowed & $1.27(1.14-1.42)$ & $1.22(1.10-1.36)$ & $1.21(1.08-1.35)$ & $1.19(1.07-1.22)$ \\
\hline \multicolumn{5}{|l|}{ Country of origin } \\
\hline Sweden & 1.00 & 1.00 & 1.00 & 1.00 \\
\hline Other Nordic countries & $1.23(1.07-1.40)$ & $1.20(1.05-1.38)$ & $1.18(1.03-1.35)$ & $1.12(0.97-1.28)$ \\
\hline Other European & $1.51(1.30-1.75)$ & $1.48(1.27-1.72)$ & $1.47(1.26-1.71)$ & $1.39(1.19-1.62)$ \\
\hline Rest of the world & $1.83(1.45-2.31)$ & $1.65(1.30-2.09)$ & $1.63(1.29-2.08)$ & $1.49(1.17-1.90)$ \\
\hline \multicolumn{5}{|l|}{ Highest level of education } \\
\hline University education & 1.00 & 1.00 & 1.00 & 1.00 \\
\hline Upper secondary school & $1.11(1.02-1.20)$ & $1.12(1.03-1.22)$ & $1.09(1.00-1.18)$ & $1.05(0.97-1.15)$ \\
\hline Primary school ( $\leq 9 y)$ & $1.16(1.05-1.27)$ & $1.14(1.04-1.25)$ & $1.09(0.99-1.20)$ & $1.02(0.93-1.13)$ \\
\hline \multicolumn{5}{|l|}{ Type of housing } \\
\hline Own accommodation & 1.00 & 1.00 & 1.00 & 1.00 \\
\hline Rented accommodation & $1.40(1.29-1.52)$ & $1.30(1.19-1.41)$ & $1.28(1.17-1.39)$ & $1.19(1.10-1.30)$ \\
\hline Other & $2.27(1.74-2.96)$ & $1.72(1.32-2.25)$ & $1.78(1.36-2.33)$ & $1.67(1.28-2.20)$ \\
\hline \multicolumn{5}{|l|}{ Financial stress - General } \\
\hline No & 1.00 & 1.00 & 1.00 & 1.00 \\
\hline Yes & $3.22(2.65-3.90)$ & $2.89(2.38-3.51)$ & $2.84(2.33-3.45)$ & $2.59(2.13-3.15)$ \\
\hline
\end{tabular}

Note:

Model 1: adjusted by age, sex and chronic conditions

Model 2: adjusted by age, sex and health behaviors

Model 3: adjusted by age, sex, chronic conditions and health behaviors

Model 4: adjusted by age, sex, chronic condition, health behavior and social stressors (excl. Living alone)

the association between financial stress and GSs, among which health risk behavior [14], health status [1,30] and living circumstances $[35,36]$. But, it is also of note, that in our study, the association remains strong after taking all these factors into account.

The fact that older people born outside the Nordic countries have higher odds for GSs echoes earlier studies showing poorer health and higher prevalence of GSs in this population group [23, 37]. While we adjusted for contributing factors like social stressors [37], it remains unclear whether the association is a matter of higher physical vulnerability [37], less use of in-hospital care due to difference in illness presention, health illiteracy or communicaion barriers [38] or both. This population group may require particular attention, as prevention of GSs may decrease the risk of new chronic conditions and disability $[2,10,18]$.

Poorer health among single persons, divorced and widowed, has been demonstrated in various studies $[1,5$, 15]. In our study we also observe a significant association with GSs even after adjustments for chronic conditions, health behavior and social stressors (excluding living alone to avoid overadjustment when analysing civil status).
To date, study results on the association between education and GSs are mixed [1, 5, 13, 18]. We find a significant association between education and GSs in the crude analyses, but not in the adjusted ones suggests that health status, health behavior and social stress contribute largely to explain the association. With the majority of older people, in this study, holding a primary school degree as their highest educational attaintment, the low level of discrimination between levels of education may also affect the results [39].

Besides the large sample size, another strengths were the availability of different self-reported geriatrics syndromes in this population of older swedish community-dwellers from the Stockholm County Council, Public Health Survey. The same protocol was applied throughout the different survey years [24]. While self-reported data is prone to misclassification, it is more suited to capture the prevalence of GSs among older community-dwellers compared to registry information as many GSs are normally not officially coded in registers [40]. While other health surveys only capture some GS, the Stockholm County Council Public Health Survey is quite unique as the questions identify all specific GSs commonly reported in other GSs studies [10, 12, 23, 31, 32]. 
However, self-reports on GSs are also prone to underreporting, as older people may be less likely to report undesirable conditions [41], or consider them as "normal" age-related conditions. It is difficult to asses the affect of underreporting on our results, but we may have underestimated the magnitude of specific single GSs.

Further limitations concern non-participation bias in the survey. Very disabled older community-dwellers may not be fit enough to respond to the survey due to physical or cognitive impairments leading to an underestimation of the prevalence of GSs. This may weaken the external validity of our study and also for example older people born outside the Nordic countries are underpresented among the participants [24]. Despite lower response-rate among some subgroups, in terms of morbidity the Stockholm County Council Public Health survey data has been shown to be generally comparable to that of the Swedish population aged $65-80$ years [42]. Those aged 80 years or older tended to be even slightly healthier than the population [42].

Our study does not allow any conclusions on causality or trajectories, as it investigates cross-sectional associations in terms of prevalence. However, some measures for social position like level of education that are stable over time, especially at the age of 65 and above, can be assumed to precede single or a set of GSs. Yet for other meassures like financial stress and type of housing a potential reverse causality could exist. A longitudinal study would be warranted to disentangle these effects and assess the risks of low social position in developing GSs.

\section{Conclusion}

In this large population-based study, there is a high prevalence of GSs among older Swedish communitydwellers. Lower social position, especially the presence of financial stress, was associated with a higher risk of GSs independent of health behaviour and health status. More attention is required on social position when adressing,delaying or even preventing GSs among older community-dwellers.

\section{Supplementary information}

Supplementary information accompanies this paper at https://doi.org/10. 1186/s12877-019-1295-8.

Additional file 1. Additional information on study design and sample.

Additional file 2: Table S1. Showing the association between social position and number and specific types of geriatric syndromes, adjusted by age, sex, chronic condition, health behavior, social stressors (excl. living alone).

\section{Abbreviations}

BMI: Body mass index; GS: Geriatric syndrome; LISA: Database for health insurance and labor market studies

\section{Acknowledgements}

none.

\section{Authors' contributions}

CR conceived the study idea and design in collaboration with $J M, L L$ and $Y L$. CR performed the statistical analyses and wrote the first draft of the manuscript; JM, LL, YL, UB, SEDR and KJ contributed to the interpretation of the results and writing of the mansuscript. All authors approved the final version for submission.

Funding

There is no funding to declare.

\section{Availability of data and materials}

The datasets used and/or analysed during the current study are available from the corresponding author on reasonable request.

\section{Ethics approval and consent to participate}

The Stockholm Regional Ethical Review Board granted ethical approval (case numbers: 2011/344-31/5, 2013/466-32, 2016/984-32 and 2016/1932-31/5). All participants gave their informed consents by filling in the questionnaire and sending it back.

Consent for publication

Not applicable

\section{Competing interests}

The authors declare that they have no competing interests.

\section{Author details}

${ }^{1}$ Department of Public Health Sciences, Karolinska Institutet, Widerströmska huset 4:th floor, Tomtebodavägen 18A, 17177 Stockholm, SE, Sweden. ${ }^{2}$ Department of Health Sciences, Community and Occupational Medicine, University of Groningen, University Medical Center Groningen, Antonius Deusinglaan 1, FA10, 9713, AV, Groningen, The Netherlands. ${ }^{3}$ Department of Internal Medicine, Center for Geriatric Medicine, University of Groningen, University Medical Center Groningen, Hanzeplein 1, Groningen 9713 GZ, The Netherlands. ${ }^{4}$ Department of Medical Epidemiology and Biostatistics, Karolinska Institutet, Nobels väg 12A, Stockholm 171 77, Sweden.

Received: 10 May 2019 Accepted: 26 September 2019

Published online: 15 October 2019

\section{References}

1. Marmot, Michael M marmot@ucl. ac. u. Social determinants of health inequalities. 2005. doi:https://doi.org/10.1016/S0140-6736(05)71146-6.

2. Clerencia-Sierra M, Calderón-Larrañaga A, Martínez-Velilla N, VergaraMitxeltorena I, Aldaz-Herce P, Poblador-Plou B, et al. Multimorbidity patterns in hospitalized older patients: associations among chronic diseases and geriatric syndromes. PLoS One. 2015;10:e0132909. https://doi.org/10.1371/ journal.pone.0132909.

3. Roland M, Paddison C. Better management of patients with multimorbidity. BMJ. 2013;346:f2510. https://doi.org/10.1136/BMJ.F2510.

4. Stringhini $S$, Carmeli $C$, Jokela M, Avendaño M, Muennig P, Guida F, et al. Socioeconomic status and the $25 \times 25$ risk factors as determinants of premature mortality: a multicohort study and meta-analysis of 1.7 million men and women. Lancet. 2017. https://doi.org/10.1016/S01406736(16)32380-7.

5. Helgadóttir B, Laflamme L, Monárrez-Espino J, Möller J, Rubenstein L, Josephson $\mathrm{K}$, et al. Medication and fall injury in the elderly population; do individual demographics, health status and lifestyle matter? BMC Geriatr. 2014;14:92. https://doi.org/10.1186/1471-2318-14-92.

6. Stringhini S, Tabak AG, Akbaraly TN, Sabia S, Shipley MJ, Marmot MG, et al. Contribution of modifiable risk factors to social inequalities in type 2 diabetes: prospective Whitehall II cohort study. BMJ. 2012;345 http://www. bmj.com/content/345/bmj.e5452.short.

7. Sadana R, Blas E, Budhwani S, Koller T, Paraje G. Healthy ageing: raising awareness of inequalities, determinants, and what could be done to improve health equity. Gerontologist. 2016;56:S178-93. https://doi.org/10. 1093/geront/gnw034.

8. Szanton SL, Seplaki CL, Thorpe RJ, Allen JK, Fried LP. Socioeconomic status is associated with frailty: the Women's health and aging studies. J Epidemiol Community Health. 2010;64:63-7. https://doi.org/10.1136/jech.2008.078428. 
9. Wastesson JW, Fors S, Parker MG, Johnell K. Inequalities in health care use among older adults in Sweden 1992-2011: a repeated cross-sectional study of swedes aged 77 years and older. Scand J Public Health. 2014;42:795-803. https://doi.org/10.1177/1403494814557150.

10. Inouye SK, Studenski S, Tinetti ME, Kuchel GA. Geriatric syndromes: clinical, research, and policy implications of a core geriatric concept. J Am Geriatr Soc. 2007;55:780-91. https://doi.org/10.1111/j.1532-5415.2007.01156.x.

11. Lane NE, Stukel TA, Boyd CM, Wodchis WP. Long-term care residents' geriatric syndromes at admission and disablement over time: an observational cohort study. Journals Gerontol Ser A. 2018. https://doi.org/10.1093/gerona/gly151.

12. Tabue-Teguo M, Grasset L, Avila-Funes JA, Genuer R, Proust-Lima C, Péres K, et al. Prevalence and co-occurrence of geriatric syndromes in people aged 75 years and older in France: results from the Bordeaux three-city study. Journals Gerontol - Ser A Biol Sci Med Sci. 2018;73:109-16. https://doi.org/ 10.1093/gerona/glx068.

13. Brown RT, Kiely DK, Bharel M, Mitchell SL. Factors associated with geriatric syndromes in older homeless adults. J Health Care Poor Underserved. 2013; 24:456-68. https://doi.org/10.1353/hpu.2013.0077.

14. Falkstedt D, Möller J, Zeebari Z, Engström K. Prevalence, co-occurrence, and clustering of health-risk behaviors among people with different socioeconomic trajectories: A population-based study. Prev Med (Baltim). 2016;93: 64-9. https://doi.org/10.1016/j.ypmed.2016.09.017.

15. Artazcoz L, Rueda S. Social inequalities in health among the elderly: a challenge for public health research. J Epidemiol Community Health. 2007; 61:466-7. https://doi.org/10.1136/jech.2006.058081.

16. Kharrazi H, Anzaldi $\sqcup$, Hernandez L, Davison A, Boyd CM, Leff B, et al. The value of unstructured electronic health record data in geriatric syndrome case identification. J Am Geriatr Soc. 2018;66:1499-507. https:/doi.org/10.1111/jgs.15411.

17. Rosso AL, Eaton CB, Wallace R, Gold R, Stefanick ML, Ockene JK, et al. Geriatric syndromes and incident disability in older women: results from the women's health initiative observational study. J Am Geriatr Soc. 2013;61: 371-9. https://doi.org/10.1111/jgs.12147.

18. Cigolle CT, Langa KM, Kabeto MU, Tian Z, Blaum CS. Geriatric conditions and disability: the health and retirement study. Ann Intern Med. 2007;147: 156. https://doi.org/10.7326/0003-4819-147-3-200708070-00004.

19. Wierenga PC, Buurman BM, Parlevliet JL, Van Munster BC, Smorenburg SM, Inouye SK, et al. Association between acute geriatric syndromes and medication-related hospital admissions. Drugs Aging. 2012;29(8):691-9. https://doi.org/10.2165/11632510-000000000-00000.

20. Rausch C, Laflamme L, de Rooij SE, Bültmann U, Möller J. Injurious falls and subsequent adverse drug events among elderly - a Swedish populationbased matched case-control study. BMC Geriatr. 2017;17:202. https://doi.org/ 10.1186/s12877-017-0594-1.

21. Yang D-C, Lee J-D, Huang C-C, Shih H-I, Chang C-M. Association between multiple geriatric syndromes and life satisfaction in community-dwelling older adults: a nationwide study in Taiwan. Arch Gerontol Geriatr. 2015;60:437-42.

22. Greene M, Justice AC, Covinsky KE. Assessment of geriatric syndromes and physical function in people living with HIV. Virulence. 2017;8:586-98. https:// doi.org/10.1080/21505594.2016.1245269.

23. Liang Y, Rausch C, Laflamme L, Möller J. Prevalence, trend and contributing factors of geriatric syndromes among older swedes: results from the Stockholm County Council public health surveys. BMC Geriatr. 2018;18:322. https://doi.org/10.1186/s12877-018-1018-6.

24. Svensson AC, Fredlund P, Laflamme L, Hallqvist J, Alfredsson L, Ekbom A, et al. Cohort profile: the Stockholm public health cohort. Int J Epidemiol. 2013;42:1263-72.

25. Goldberg DP, Gater R, Sartorius N, Ustun TB, Piccinelli M, Gureje O, et al. The validity of two versions of the GHQ in the WHO study of mental illness in general health care. Psychol Med. 1997;27:191-7.

26. Sacker A, Bartley M, Firth D, Fitzpatrick R. Dimensions of social inequality in the health of women in England: occupational, material and behavioural pathways. Soc Sci Med. 2001;52:763-81.

27. O'Neill J, Tabish H, Welch V, Petticrew M, Pottie K, Clarke M, et al. Applying an equity lens to interventions: using PROGRESS ensures consideration of socially stratifying factors to illuminate inequities in health. J Clin Epidemiol. 2014;67:56-64. https://doi.org/10.1016/J.JCLINEPI.2013.08.005.

28. Lennartsson C, Heimerson I. Alders Halsa (health of elders). Sweden: Vasteras; 2009

29. Idler EL, Benyamini Y. Self-rated health and mortality: a review of twentyseven community studies. J Health Soc Behav. 1997;38:21. https://doi.org/10. $2307 / 2955359$
30. Tinetti ME, Inouye SK, Gill TM, Doucette JT. Shared risk factors for falls, incontinence, and functional dependence. Unifying the approach to geriatric syndromes. JAMA. 1995;273:1348-53.

31. Noguchi N, Blyth FM, Waite LM, Naganathan V, Cumming RG, Handelsman DJ, et al. Prevalence of the geriatric syndromes and frailty in older men living in the community: the Concord health and ageing in men project. Australas J Ageing. 2016;35:255-61. https://doi.org/10.1111/ajag.12310.

32. Kane RL, Shamliyan T, Talley K, Pacala J. The association between geriatric syndromes and survival. J Am Geriatr Soc. 2012;60:896-904.

33. Gu D, Yang F, Sautter J, Fried L, Tangen C, Walston J, et al. Socioeconomic status as a moderator between frailty and mortality at old ages. BMC Geriatr. 2016;16:151. https://doi.org/10.1186/s12877-016-0322-2.

34. Okamoto S. Socioeconomic factors and the risk of cognitive decline among the elderly population in Japan. Int J Geriatr Psychiatry. 2019;34:265-71. https://doi.org/10.1002/gps.5015.

35. Ryu E, Juhn YJ, Wheeler PH, Hathcock MA, Wi C-I, Olson JE, et al. Individual housing-based socioeconomic status predicts risk of accidental falls among adults. Ann Epidemiol. 2017;27:415-420.e2. https://doi.org/10.1016/J. ANNEPIDEM.2017.05.019.

36. Wanchai A, Phrompayak D. Social Participation Types and Benefits on Health Outcomes for Elder People: a Systematic Review. Ageing Int. 2018:111. https://doi.org/10.1007/s12126-018-9338-6.

37. Silveira E, Skoog I, Sundh V, Allebeck P, Steen B. Health and well-being among 70-year-old migrants living in Sweden--results from the $\mathrm{H} 70$ gerontological and geriatric population studies in Göteborg. Soc Psychiatry Psychiatr Epidemiol. 2002;37:13-22.

38. Albin B, Hjelm K, Ekberg J, Elmståhl S. Utilization of in-hospital care among foreign-born compared to native swedes 1987-1999. Nurs Res Pract. 2012; 2012:713249. https://doi.org/10.1155/2012/713249.

39. Batljan I, Lagergren M, Thorslund M. Population ageing in Sweden: the effect of change in educational composition on the future number of older people suffering severe ill-health. Eur J Ageing. 2009;6:201-11. https://doi. org/10.1007/s10433-009-0120-1.

40. Ugboma I, Syddall HE, Cox V, Cooper C, Briggs R, Sayer AA. Coding geriatric syndromes: how good are we? CME J Geriatr Med. 2008;10(1):34-6.

41. Knäuper B, Carrière $K$, Chamandy $M, X u$ Z, Schwarz N, Rosen NO. How aging affects self-reports. Eur J Ageing. 2016;13:185-93. https://doi.org/10.1007/ s10433-016-0369-0.

42. Kelfve S, Lennartsson C, Agahi N, Modig K. Do postal health surveys capture morbidity and mortality in respondents aged 65 years and older? A registerbased validation study. Scand J Public Health. 2015;43:348-55. https://doi. org/10.1177/1403494815575340.

\section{Publisher's Note}

Springer Nature remains neutral with regard to jurisdictional claims in published maps and institutional affiliations.
Ready to submit your research? Choose BMC and benefit from:

- fast, convenient online submission

- thorough peer review by experienced researchers in your field

- rapid publication on acceptance

- support for research data, including large and complex data types

- gold Open Access which fosters wider collaboration and increased citations

- maximum visibility for your research: over $100 \mathrm{M}$ website views per year

At BMC, research is always in progress.

Learn more biomedcentral.com/submissions 